\title{
Migration of cyantraniliprole in fractured soils: calibration of pesticide leaching model by using experimental data
}

\author{
Aleksandra Belik $^{1 *}$, Anna Kokoreva ${ }^{1,2}$, and Victoria Kolupaeva ${ }^{1}$ \\ ${ }^{1}$ All-Russia Research Institute of Phytopathology, 143050, Bolshie Vyazemy, Russia \\ ${ }^{2}$ Moscow State University, 119991, Moscow, Russia
}

\begin{abstract}
The phenomenon of preferential migration of substances can increase the risk of pesticides. In the first year of the experiment, in 7 days after application cyantraniliprole penetrated to a depth of $25 \mathrm{~cm}$ in agrosoddy-podzolic soil. In the next year on the 7th day after application the pesticide was detected at a depth of $15 \mathrm{~cm}$. The pesticide migrated deeper than the unconfigured PERL model took into account. The calibration of the PERL model by using experimental data (soil experimental support) allowed to reduce the error of prediction. The obtained data can be used to create new standard soil and climate scenarios for pesticide leaching models.
\end{abstract}

\section{Introduction}

The study of pesticide migration in soils requires an understanding of the mechanisms of substance movement with water flows. In well-structured soils, the presence of macropores and cracks leads to a rapid flow of soil solution [1,2], resulting in uneven moistening. The solution penetrates to a considerable depth, practically without interacting with the surrounding soil matrix and bypassing most of the soil pore space (stagnant zone) [3]. The phenomenon of preferential migration of substances can increase the risk of pesticides due to the possible pesticide migration in groundwater. Such situation can be observed in soddypodzolic soils, which are typical for Moscow oblast.

Experimental study of pesticide migration is a difficult process with significant financial costs, therefore the method of mathematical modeling is often used to obtain predicted concentrations of pesticide in environmental objects. However, it is important to know how well the models predict the migration of pesticides in soils with different pore space. This requires checking the adequacy of the models by comparing the predicted values with the experimental data. The models predicting the pesticide behavior in soils have different approaches to describing the migration process. The models with a complex mathematical apparatus have a significant drawback - the abundance of input parameters of experimental support [3]. Therefore, calibration of simpler pesticide leaching models by using the experimentally determining parameters, which can physically reasonably take into account preferential migration, is actual.

*Corresponding author: belikalexandra@gmail.com 
In the process of state registration of pesticides in Russia for ecological risk assessment of pesticides the PEARL model is used. Thus, the main goal of this work was to calibrate the PEARL model by using the field studies of cyantraniliprole migration with experimentally determined pore space parameters of the studied soils.

\section{Objects and Methods}

\subsection{Pesticide}

Cyantraniliprole is an active substance with insecticidal activity for a wide range of crops. It is non-volatile, moderately persistent $\left(\mathrm{DT}_{50 \text { geomean lab. }}=34.4\right.$ days $)$ and medium-mobility $\left(\mathrm{K}_{\mathrm{oc}}\right.$ average $=241 \mathrm{ml} / \mathrm{g}$ ) substance [4].

\subsection{Soils}

An agrosoddy-podzolic soil (Eutric Albic Glossic Retisol (Abruptic, Loamic, Aric, Cutanic) [5] was chosen for the experiments, it's typical soil for Moscow oblast and has preferential flows. Some properties of this soils are shown in Table 1.

Table 1. Some physical and chemical properties of investigated soil.

\begin{tabular}{|c|c|c|c|c|c|c|c|c|c|c|}
\hline \multirow{2}{*}{$\begin{array}{c}\text { Hori- } \\
\text { zon }\end{array}$} & \multirow{2}{*}{$\begin{array}{c}\text { Depth, } \\
\text { cm }\end{array}$} & \multirow{2}{*}{$\begin{array}{c}\text { Corg. } \\
\%\end{array}$} & \multirow{2}{*}{$\mathbf{p H}_{\mathbf{w}}$} & \multirow{2}{*}{$\underset{\mathrm{g} / \mathrm{cm}^{3}}{\mathrm{\rho b}}$} & \multirow{2}{*}{$\stackrel{\rho s,}{\mathrm{~g} / \mathrm{cm}^{3}}$} & \multirow{2}{*}{$\begin{array}{c}\mathbf{\varepsilon} \\
\mathbf{c m}^{3 /} \\
\mathbf{c m}^{3}\end{array}$} & \multicolumn{3}{|c|}{ Particle size, $\%$} & \multirow{2}{*}{$\begin{array}{c}\mathbf{K} \mathbf{f} \\
\mathbf{m} / \\
\text { day }\end{array}$} \\
\hline & & & & & & & Sand & Silt & Clay & \\
\hline $\mathrm{P}$ & $0-36$ & 1.07 & 6.52 & 1.20 & 2.6 & 0.54 & 10.6 & 87.9 & 1.5 & 0.14 \\
\hline EL & $36-42$ & 0.26 & 6.29 & 1.35 & 2.78 & 0.51 & 5.2 & 93.5 & 1.3 & 0.14 \\
\hline BEL & $42-51$ & 0.23 & 6.07 & 1.28 & 2.72 & 0.53 & 10.4 & 89 & 0.6 & 0.43 \\
\hline $\mathrm{BT}_{1}$ & $51-80$ & 0.22 & 5.66 & 1.43 & 2.72 & 0.47 & 12.7 & 87.3 & 0 & 0.38 \\
\hline $\mathrm{BT}_{2}$ & $80-129$ & 0.16 & 6.18 & 1.34 & - & - & 15.4 & 84.6 & 0 & 0.33 \\
\hline $\mathrm{BC}$ & $>129$ & 0.17 & 7.15 & 1.25 & - & - & 16.8 & 83.1 & 0.1 & 0.16 \\
\hline
\end{tabular}

\subsection{Field experiment}

The pesticide was applied to a $25 \mathrm{~m}^{2}$ plot in the spring at doses of $0.74 \mathrm{~kg} / \mathrm{ha}$ in the first year and $0.20 \mathrm{~kg} / \mathrm{ha}$ in the second year. Before each application, the soil was treated with glyphosate, all weeds were removed, and soil was digging. Soil samples for the determination of residual pesticide were collected by the drilling method $0,7,53,101$ and 351 days after the first treatment, and $0,7,14,29,64,102,343$ days after second treatment of soil with the pesticide at vertical intervals of $5 \mathrm{~cm}$; two mixed samples were then composed from 10 individual samples each, and the content of pesticide in them was determined by liquid chromatography. Temperature loggers were installed on the experimental plot at the depths of 5,15 , and $30 \mathrm{~cm}$, which recorded temperature every hour; the water content was determined in soil layers by thermogravimetry at each sampling time. Daily weather data (rainfall, solar radiation, maximum and minimum temperature, wind speed and relative humidity) were obtained directly in the field by using a portable weather station.

\subsection{Model PEARL 4.4.4}

In this model the solute transport in soils is based on the convective diffusion equation. In the model, the soil is divided into 3 domains: matrix and two macropore domains, each of which includes static and dynamic pores: 1 - interconnected pores passing throughout the 
profile (main bypass domain) and 2 - separate pores terminating at different depths, (internal catchment domain) $[6,7]$.

\section{Results and discussion}

In the first year of the experiment, in 7 days after application cyantraniliprole penetrated to a depth of $25 \mathrm{~cm}$, during the entire first year of the study the pesticide wasn't detected below this layer. According to previous studies [8], cyantraniprole didn't migrate below $20 \mathrm{~cm}$ in the studied soils of the Russian Federation. The deeper penetration of the pesticide in our experiment in the first week after application may be due to both the structural features of the soil pore space, and the dry period before the experiment and $10 \mathrm{~mm}$ on 5 th day. Indeed, one of the mechanisms of activation of preferential migration paths is a combination of factors: lack of precipitation for some time, unsaturated conditions and then heavy rainfall $[1,3,9]$.

In the next year on the 7 th day after application the pesticide was detected at a depth of $15 \mathrm{~cm}$. Then, on the 29th day, cyantraniprole reached a depth of $20 \mathrm{~cm}$ and didn't migrate below. In the second year the weather conditions after application of pesticide were very different from the first year: before the application the soil had enough time for saturation, it rained for several days (Fig. 1).

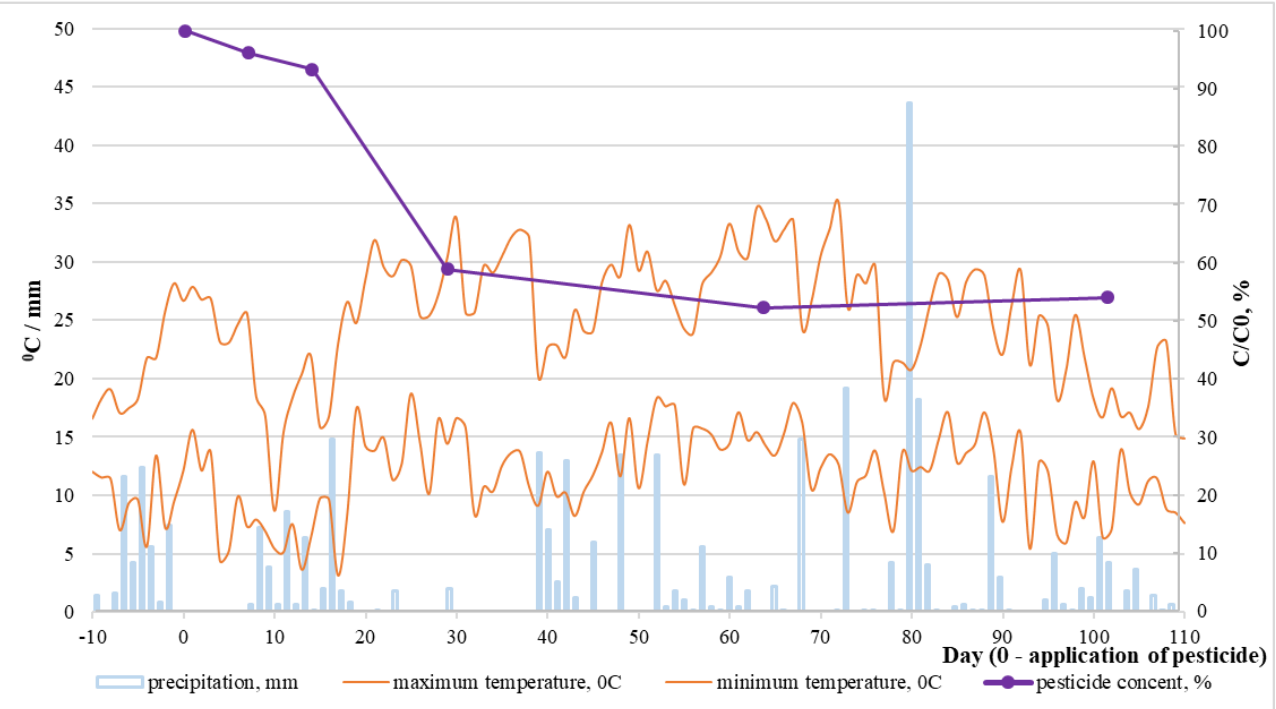

Fig. 1. Dynamics of the total content of cyantraniliprole in investigated soil in the second year.

To work pesticide leaching model, it is necessary to have initial conditions, conditions at the lower and upper boundaries and experimental support (physical and chemical properties of soils, toxicants). The parametrization of the soil experimental support was made based on the soil properties shown in Table 1. Data on the physicochemical properties of cyantraniliprole were borrowed from the conclusions of the European Food Safety Authority [4]. $\mathrm{DT}_{50}=49.9$ days was used; it was found by the All-Russia Research Institute of Phytopathology for this soil type [10].

Before predicting cyanthraniliprol migration, it is important to evaluate the work of the soil block of the PEARL model. It is necessary to compare the obtained experiment and predicted values. SRMSE (Scaled root mean square error) is often used to assess the adequacy of models describing the behavior of pesticides [11, 12]. Since pesticide degradation takes place together with the migration process, it was necessary to check how 
accurately PEARL predicts soil temperature from weather data. The comparison of the calculated data with the readings of temperature loggers showed good forecast accuracy (Fig. 2).

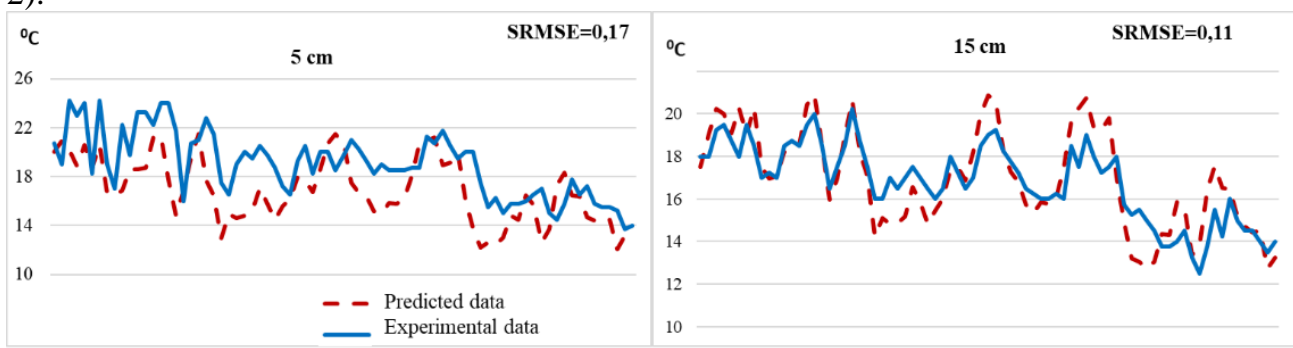

Fig. 2. Experimental and predicted temperature data.

The migration of substances in the soil occurred mainly with water flows, so the next step was to check the quality of the moisture forecast. The significant errors were found that are expected to increase with depth. SRMSEs were 0.07-0.14 in the upper layers and reached 0.34 in the deep layers $(30-35 \mathrm{~cm})$. Based on the received data, it becomes necessary to further calibration the model. According to previous studies evaluating the sensitivity of the water block to the input parameters of the PEARL model [13], the greatest influence on the forecast of soil moisture is exerted by approximation parameters of soil water retention curve and filtration coefficient. By sequentially selecting the numerical values of the sensitive parameters, only the filtration coefficient values were calibrated within the limits corresponding to the studied type of soils, it led to reduce the forecast error (for example, for a layer of $30-35 \mathrm{~cm}$ to 0.24 ). The comparison of adjusted and unadjusted models using the Williams-Klute test [14] was shown that the setting of water block of the PEARL model led to an improvement in the forecast: at p-level $=0.029675$, the t-value equal to -2.267001 .

The next step was to analyze the prediction of the behavior of the pesticide in the soil. In this paper, simulation of the pesticide migration was conducted for second year of the study. In the first days after application, the pesticide migrated deeper than the PERL model took into account, this phenomenon may be due to the preferential migration paths in agro-soddypodzolic soil. The PEARL model has a parameter 'dispersivity length' - a coefficient that takes into account the vertical heterogeneity of the moisture-conducting pore space. Higher values of this parameter are typical for soils with a high clay content and uneven pore space with preferential migration flows [15]. In previous works [16] it was shown that the dispersivity length can be used to configure the PERL model. In our previous studies [17] the values of dispersivity length were determined for monoliths $(\mathrm{d}=10 \mathrm{~cm}, \mathrm{~h}=30 \mathrm{~cm})$ of agrosoddy-podzolic soil in laboratory conditions. But for subsequent modeling in experimental support it is necessary to divide the soil profile into layers, and a length of 30 $\mathrm{cm}$ may exceed the horizon thickness, a "scale problem" arises. Therefore, it was decided to conduct another series of filtration column experiments with small monoliths $(\mathrm{d}=5 \mathrm{~cm}, \mathrm{~h}=10$ $\mathrm{cm})$, the obtained values of dispersivity length are presented in the Table 2.

Table 2. Laboratory dispersivity lengths for small monoliths $(\mathrm{d}=5 \mathrm{~cm}, \mathrm{~h}=10 \mathrm{~cm})$.

\begin{tabular}{|c|c|c|}
\hline Depth, cm & Filtration rate, cm/day & Dispersivity length, cm \\
\hline $0-10$ & 132 & 5.0 \\
\hline $10-20$ & 57 & 3.5 \\
\hline $20-30$ & 97 & 7.5 \\
\hline $30-40$ & 62 & 13.0 \\
\hline $40-50$ & 55 & 5.6 \\
\hline $50-60$ & 99 & 5.6 \\
\hline
\end{tabular}


The method of field determination of dispersivity lengths is described in detail in an article with colleagues [18]. In this work, the values shown in Fig. 3 were used.

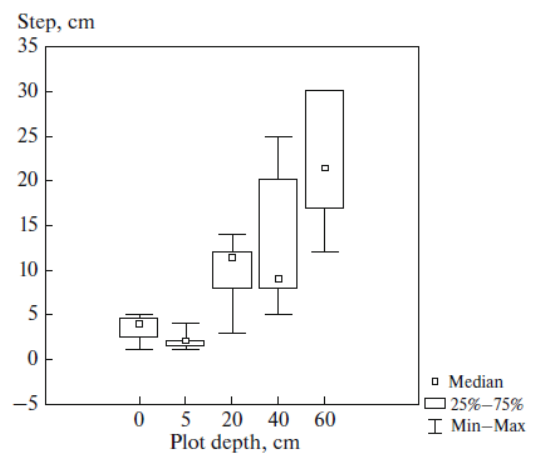

Fig. 3. Statistics of the field determinations of dispersivity length.

Based on a comparison of experimental and predicted results of the dynamics of the pesticide distribution in the soil profile and the analysis of SRMSE (Table 3), it can be stated that the results of modeling the pesticide migration with the dispersivity length $=5 \mathrm{~cm} \mathrm{[6]} \mathrm{and}$ with the values determined in laboratory experiments were very close. However, modeling with using field values of dispersivity length better described the behavior of the pesticide, especially in the lower layers, reducing SRMSE (Table 3). Thus, the experimentally determined values of dispersivity length for a particular soil, on which the pesticide is applied, can serve as a tool for configure the PEARL model.

Table 3. SRMSE of predicting the residual pesticide contents in soil at different dispersivity lengths for the second year.

\begin{tabular}{|c|c|c|c|}
\hline \multirow{2}{*}{ Depth, cm } & \multicolumn{3}{|c|}{ Dispersivity length } \\
\cline { 2 - 4 } & $\mathbf{5} \mathbf{~ c m}$ & Laboratory & Field \\
\hline $0-10$ & 0.23 & 0.23 & 0.23 \\
\hline $10-15$ & 0.75 & 0.76 & 0.57 \\
\hline $15-20$ & 1.05 & 1.09 & 0.80 \\
\hline Soil profile & 0.19 & 0.19 & 0.19 \\
\hline
\end{tabular}

\section{Conclusions}

The obtained results allow to assess the significance of the preferential migration flows in the behavior of pesticides in fractured soils. The obtained data (soil experimental support and materials for calibration of the mathematical model PEARL) can be used to create new standard soil and climate scenarios for pesticide leaching models, which used in registration process in the Russian Federation.

\section{References}

1. W. Kördel, M. Klein, Pure Appl. Chem., 78 (5), 1081-1090 (2006)

2. T. Katagi, Rev. Environ. Contam. Toxicol., 221, 1-105 (2013)

3. J. Simunek, N. Jarvis, M.Th. van Genuchten, A.Gardenas, Journal of Hydrology., 272, 14-35 (2003) 
4. Conclusion on the peer review of the pesticide risk assessment of the active substance cyantraniliprole, EFSA J., 12(9):3814 (2014)

5. World Reference Base for Soil Resources, International soil classification system for naming soils and creating legends for soil maps. World Soil Resources Reports No. 106. (FAO, Rome, 2014)

6. A. Tiktak, R. F. A. Hendriks, J. J. T. I. Boesten, Pestic. Manage. Sci., 68, 290-302 (2011)

7. F. van den Berg, A. Tiktak, J. J. T. I. Boesten, A.M. A. van der Linden, PEARL Model for Pesticide Behavior and Emissions in Soil-Plant Systems, 61, 134 (Statutory Research Tasks Unit for Nature and Environment, Wageningen, 2016)

8. The study of the decomposition and migration of cyantraniliprole in the soils of the Russian Federation. Report on research work for 2012 (Center for Ecopesticidal Research «Epicenter», Moscow, 2013)

9. N. Jarvis, J. Koestel, M. Larsbo, Vadose Zone J., 15(12) (2016)

10. V. N. Kolupaeva, V. S. Gorbatov, I. V. Nyukhina, Vestn. Novosib. Gos. Agrar. Univ., 2 (39), 82-91 (2016)

11. A. A. Smetnik, Yu. Ya. Spiridonov, E. V. Shein, Migration of Pesticides in Soils (Russian Research Institute of Phytopathology, Moscow, 2005

12. I. Dubus, S. Beulke, C. Brown, Pestic. Manage. Sci., 58, 745-758 (2002)

13. A. A. Kokoreva, A. B. Umarova, V. S. Gorbatov, Vestn. Orenb. Gos. Univ., 3, 123-127 (2007)

14. E.V. Shein, M.A. Mazirov, A.A. Korchagin, A.B. Umarova, V.M. Goncharov, C.I. Zinchenko, A.V. Dembovetsky, Regression analysis in soil science (VISU Publishing House, Vladimir, 2016)

15. J. Vanderborght and H. Vereecken, Vadose Zone J., 6, 29-52 (2007)

16. E. Shein, A. Belik, A. Kokoreva, V. Kolupaeva, P. Pletenev Prediction of Pesticide Migration in Soils: the Role of Experimental Soil Control, Moscow University Soil Science Bulletin, 72(4), 185-190 (2017)

17. E. V. Shein, A. A. Kokoreva, V. N. Kolupaeva, A. A. Belik, P.A. Pletenev, Agrokhim. Vestn., 6, 20-23 (2016)

18. E.V. Shein, A.A. Belik, A.A. Kokoreva, V.N. Kolupaeva, Eurasian Soil Sci. 51(7), 797802 (2018) 